\title{
Entendendo o Tempo e o Clima na América do Sul
}

\author{
Michelle Simões Reboita \\ UNIFEI, Inst. de Recursos Naturais (IRN) \\ mireboita@gmail.com \\ Nisia Krusche \\ FURG, Centro de Ciências Computacionais \\ nkrusche@furg.br \\ Tércio Ambrizzi \\ USP, Depto. de Ciências Atmosféricas \\ ambrizzi@model.iag.usp.br \\ Rosmeri Porfírio da Rocha \\ USP, Depto. de Ciências Atmosféricas \\ rosmerir@model.iag.usp.br
}

\begin{abstract}
Underrstanding Weather and Climate in South America: South America (SA) has a diversified geography that enables the development and action of different atmospheric systems. These systems contribute to the spatial and temporal non-homogeneity of precipitation patterns. This study has as purposes: (a) to provide basic concepts from weather and climate, (b) to present the precipitation climatology and (c) to describe the atmospheric systems that contribute to the diverse annual cycles of precipitation in each region of the $S A$. The wet season in the continent is usually in the summer and the dry season is the winter. In these seasons different atmospheric systems are responsible by precipitation.
\end{abstract}

KEYWORDS: weather, climate, precipitation, South America

RESUMO A América do Sul (AS) possui uma geografia diversificada, propícia ao desenvolvimento e atuação de diferentes sistemas atmosféricos que contribuem para não-homogeneidade espacial e temporal da precipitação. Diante disso, os objetivos deste estudo são: (a) discutir os conceitos básicos de tempo e clima, (b) apresentar a climatologia de precipitação no continente sul-americano e (c) descrever os sistemas atmosféricos que contribuem para os diferentes ciclos anuais de precipitação nos diversos setores da $A S$, com base em revisão da literatura. De modo geral, a estação chuvosa da $A S$ é o verão e a seca, o inverno. Nessas estações do ano, diferentes sistemas atmosféricos são responsáveis pela precipitação.

PALAVRAS-CHAVES: tempo, clima, precipitação, América do Sul

\section{Introdução}

A América do Sul (AS) possui grande extensão latitudinal, ocupando desde áreas equatoriais até de latitudes médias; portanto, diferentes regimes climáticos são encontrados no continente.

Assim, o objetivo deste trabalho é apresentar os conhecimentos meteorológicos básicos para o entendimento do tempo e clima vigentes no continente sul-americano.

\section{O Sol como Fonte de Energia}

A principal fonte de energia do planeta Terra é o Sol. A energia que chega aquece primeiramente a superfície terrestre e depois, por intermédio de alguns processos físicos entre a superfície e a atmosfera, o ar adjacente também é aquecido. Entretanto, o aquecimento da Terra não ocorre de maneira uniforme entre polos e equador. Devido à forma da Terra, os raios solares atingem a região tropical 


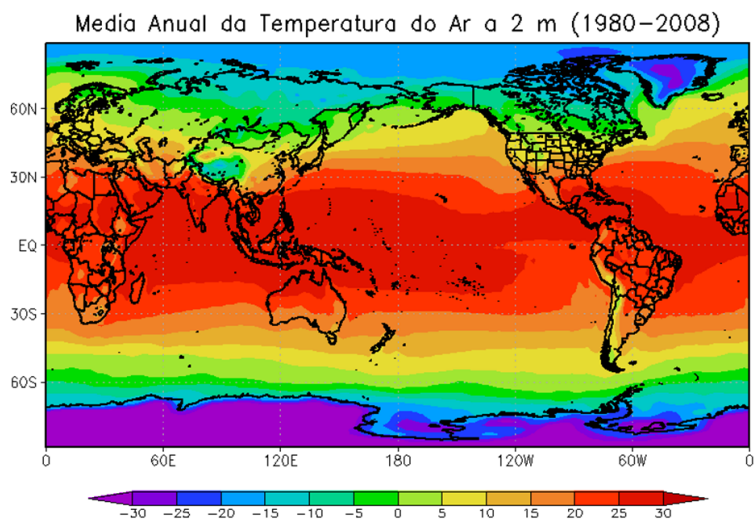

Figura 1. Média anual (1980-2008) da temperatura do ar $\left({ }^{\circ} \mathrm{C}\right)$ a 2 metros de altura. Dados obtidos da reanálise do NCEP/NCAR (Kalnay et al. 1996)

quase perpendicularmente à superfície, enquanto nas regiões mais próximas aos polos a incidência é oblíqua. Isso implica numa maior concentração de energia por unidade de área próximo ao equador do que nos polos. Portanto, as regiões tropicais se aquecem mais do que as polares (Fig. 1).

O padrão espacial da temperatura média do ar próxima à superfície, mostrado na Figura 1, não é constante ao longo do ano, pois ocorre uma migra-
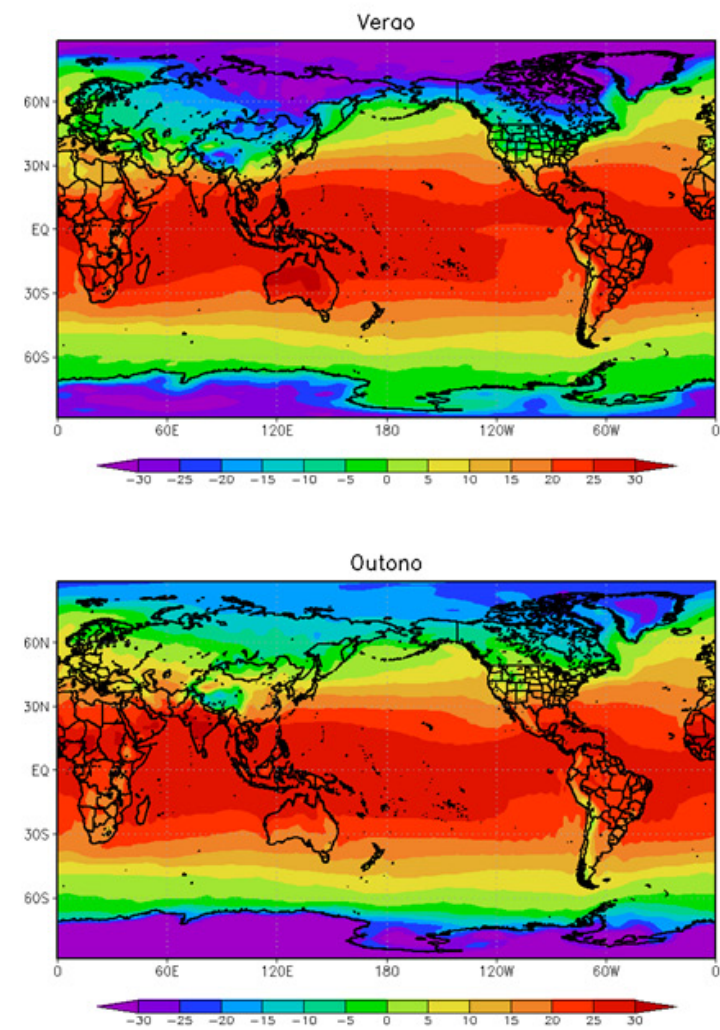

ção latitudinal das regiões mais quentes (Fig. 2) e isso é decorrente de dois fatores: a inclinação do eixo de rotação da Terra em relação ao seu plano orbital e o movimento de translação do planeta ao redor do Sol. À medida que a Terra realiza o movimento de translação, o seu eixo de inclinação permite que um dos Hemisférios (Norte ou Sul) fique mais exposto ao Sol. Com relação ao Hemisfério Sul, este fica voltado para o Sol entre dezembro e março, o que caracteriza o verão austral e que tem início no dia 22 de dezembro quando os raios solares atingem perpendicularmente o Trópico de Capricórnio $\left(23,5^{\circ} \mathrm{S}\right)$. Entre junho e agosto, é o Hemisfério Norte que fica voltado para o Sol. O início do verão boreal ocorre em 21 de junho quando os raios solares ficam perpendiculares ao Trópico de Câncer $\left(23,5^{\circ} \mathrm{S}\right)$. Nos demais períodos do ano, o Sol atinge perpendicularmente a região equatorial. Para o caso do Hemisfério Sul, quando o Sol atinge perpendicularmente o equador após o verão austral (inverno austral), em 21 de março (23 de setembro), inicia-se o outono (primavera).

É importante destacar que a região tropical não consegue emitir para o espaço toda a energia
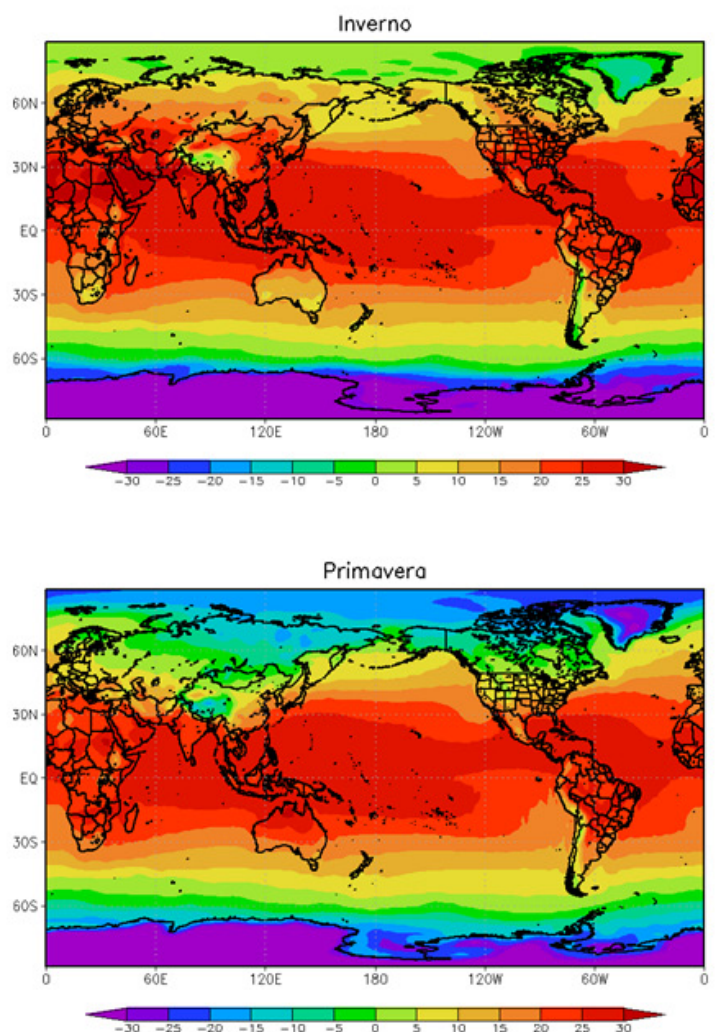

Figura 2. Média sazonal (1980-2008) da temperatura do ar $\left({ }^{\circ} \mathrm{C}\right)$ a $2 \mathrm{~m}$ de altura. Dados obtidos da reanálise do NCEP/ NCAR (Kalnay et al. 1996) 
que recebe do Sol, em parte devido à quantidade de nuvens existente nesta região, havendo um saldo positivo de energia. Por outro lado, devido à presença de gelo/neve nas regiões polares, estas emitem mais do que recebem o que acarreta um saldo negativo de energia. Então, como manter as condições climáticas observadas, ou seja, onde os polos são excessivamente frios e os trópicos excessivamente quentes? A circulação geral da atmosfera $e$ dos oceanos responde esta questão, pois o aquecimento diferencial da atmosfera induz a formação dos ventos que transportam ar quente e úmido da região tropical para os polos e também transportam ar frio e seco dos polos para a região tropical. No oceano, há geração das correntes marítimas e o processo de transferência de calor entre trópicos e polos é similar ao da atmosfera. Nota-se, portanto, que há uma redistribuição de energia para manter o equilíbrio térmico da Terra. Neste estudo, será dado enfoque apenas para os sistemas atmosféricos.

\section{Circulação Geral da Atmosfera}

$\mathrm{Na}$ região equatorial, o intenso aquecimento solar causa a ascensão do ar e formação de muitas nuvens e de chuva. Depois de subir, o ar na alta troposfera $(\sim 10 \mathrm{~km}$ de altura) desloca-se em direção aos polos em ambos os hemisférios. Durante o deslocamento o ar sofre resfriamento, o que o torna mais denso e propicia sua subsidência (movimentos descendentes) próximo de $20^{\circ}-30^{\circ}$ de latitude em ambos os hemisférios. Este processo aumenta o peso da coluna atmosférica dando origem a um cinturão de alta pressão em superfície conhecido com o nome de "alta subtropical" (Fig. 3). É nesta região de alta pressão que se localizam os principais desertos do globo (Sahara, Atacama, Kalahari e outros), pois quando o ar desce inibe os movimentos ascendentes na atmosfera que são fundamentais para a formação de nuvens e chuva. $\mathrm{O}$ ar que subside, ao atingir a superfície, forma um ramo que se move para os polos e outro que retorna para o equador. Este último faz parte de uma célula de circulação fechada chamada Célula de Hadley (célula formada pelo ar que ascende no equador e desce por volta de $20-30^{\circ}$ de latitude em cada hemisfério). Como a Terra está em rotação (sob ação da força de Coriolis), os ventos que se dirigem para o equador são defletidos (no Hemisfério Sul para a esquerda do movimento e no Hemisfério Norte para a direita) formando os ventos alísios de sudeste no Hemisfério Sul e os de nordeste no Hemisfério Norte (Fig. 3).

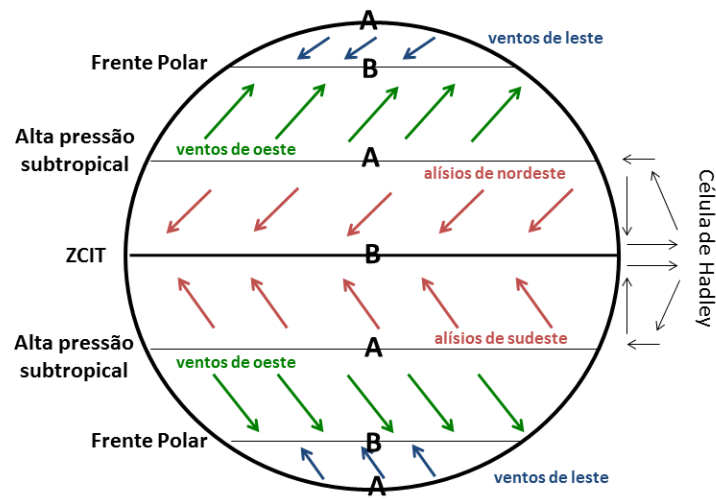

Figura 3. Representação esquemática da circulação geral da atmosfera terrestre (considerando a superfície terrestre homogênea)

Os ventos alísios, ao dirigirem-se para o equador, convergem dando origem à Zona de Convergência Intertropical (ZCIT).

Uma parte dos ventos que descem da alta para a baixa atmosfera, próximo de $20^{\circ}-30^{\circ}$ de latitude, em ambos os hemisférios, se dirige para o polo. Devido a influencia da rotação da Terra (ação da força de Coriolis) em tais ventos, tem-se ventos de oeste em superfície nas latitudes médias (Fig. 3). Próximo de $60^{\circ}$ de latitude, estes ventos convergem com os provenientes do polo em direção ao equador e o local onde ocorre a convergência é conhecido como região da Frente Polar (Fig. 3). Esta é uma região de encontro de massas de ar com propriedades térmicas distintas (massa fria e seca de origem polar e massa quente e úmida de origem tropical/ subtropical) o que favorece a formação de frentes e ciclones extratropicais. $\mathrm{Na}$ alta atmosfera (entre 9-12 km de altura) da região de latitudes médias, desde a $2^{\text {a }}$ Guerra Mundial, numerosas observações meteorológicas indicam que os ventos também são de oeste.

A figura esquemática da circulação geral da atmosfera (Fig. 3) mostra zonas contínuas de alta e baixa pressão sobre o globo, porém na atmosfera real tais zonas possuem um padrão irregular (Fig. 4), já que a superfície da Terra não é homogênea, ou seja, existem regiões de oceanos e continentes intercaladas entre si. Além disso, sobre o continente há diferentes coberturas vegetais da superfície e topografia. Tanto os oceanos quanto os continentes, bem como as diferentes coberturas da superfície, possuem diferentes valores de atrito, diferentes taxas de aquecimento e criam diferenças de pressão na horizontal, eliminando então a homogeneidade na direção leste-oeste na distribuição de pressão. Outro fator são as variações de temperatura decor- 


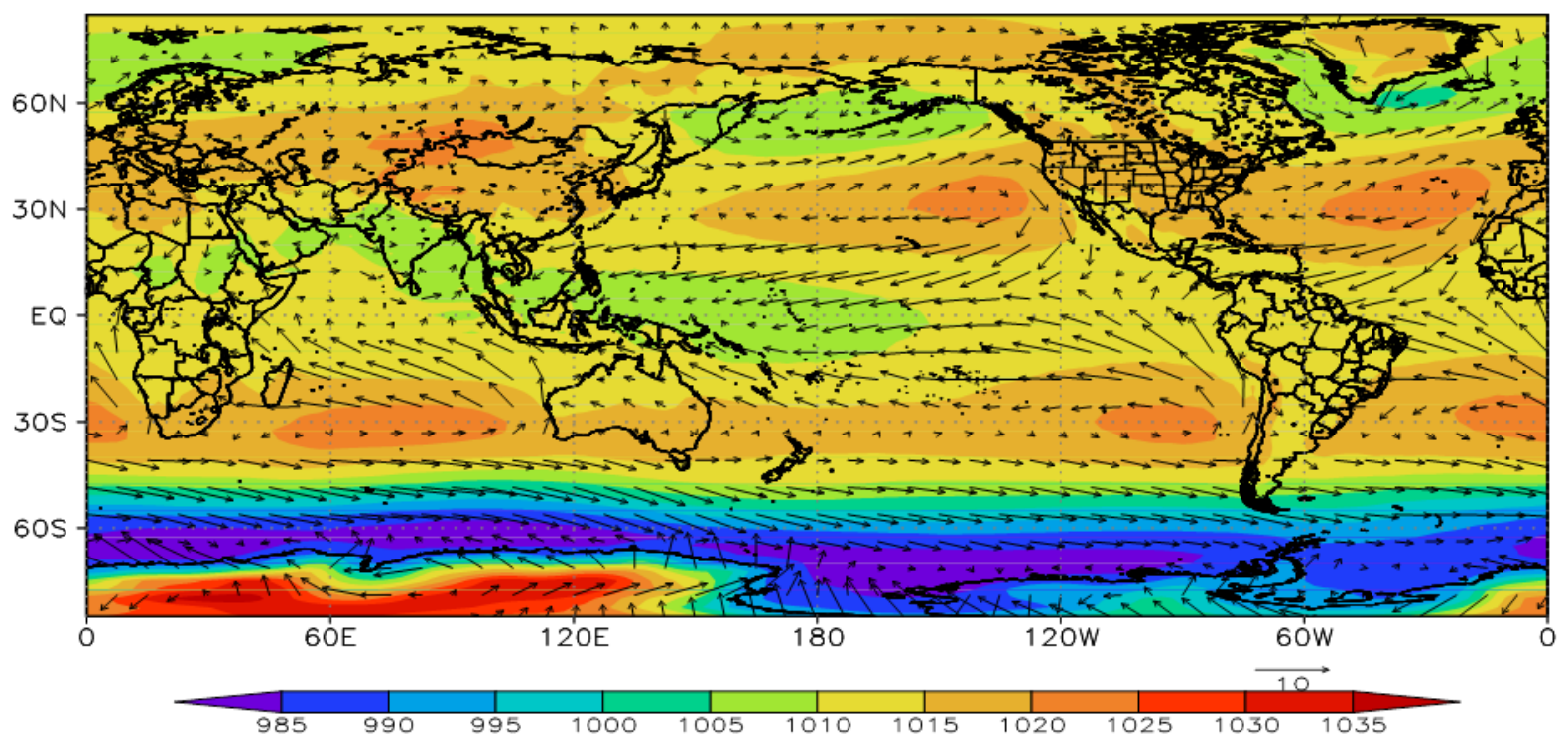

Figura 4. Circulação geral da atmosfera terrestre (média anual entre 1980 e 2008) próxima à superfície com base em dados obtidos da reanálise do NCEP/NCAR (Kalnay et al., 1996). Em cores tem-se a pressão atmosférica $(\mathrm{hPa})$ ao nível médio do mar, já as setas indicam a direção do vento. A intensidade do vento é apresentada pelo comprimento das setas

rentes da inclinação do eixo de rotação e do movimento de translação da Terra, que provocam uma migração norte-sul dos cinturões de altas e baixas pressões durante as estações do ano.

\section{Tempo e Clima na América do Sul}

\section{Definição de Tempo e Clima}

Em geral, as pessoas usam erroneamente os termos tempo e clima. O termo tempo é utilizado para se referir ao estado momentâneo da atmosfera (uma manhã ensolarada, uma tarde nublada ou chuvosa etc), enquanto o termo clima se refere ao estado médio da atmosfera que é obtido por meio da média dos eventos de tempo durante um longo período (Fig. 5). As informações utilizadas para a determinação do clima são obtidas principalmente de estações meteorológicas que registram as variáveis atmosféricas (temperatura do ar, umidade relativa do ar, pressão atmosférica, precipitação entre outras). A Organização Meteorológica Mundial (WMO 1983) define como clima médias com período de 30 anos, bem como estabelece tais períodos (1931-1960, 1961-1990, 1991-2020, etc.). Estes são denominados de normais climatológicas e possibilitam a comparação entre os dados coletados em diversas partes do planeta.

Cada região do globo possui características peculiares, como latitude, altitude, distância em relação aos oceanos e tipo de superfície, que acabam influenciando o tempo e consequentemente o clima. Portanto, essas características são denominadas de fatores ou controles climáticos e uma descrição dos mesmos é dada a seguir.

Latitude: as regiões mais próximas do equador recebem mais energia solar (são mais quentes) do que as mais afastadas em função do ângulo de incidência dos raios solares sobre a superfície do planeta.

Altitude: a temperatura do ar decresce com a altitude até, aproximadamente, $10 \mathrm{~km}$ de altura onde se localiza a parte superior da troposfera. Considerando que o Sol emita 100 unidades de energia, 51 unidades são absorvidas pela superfície terrestre, 30 são refletidas para fora da atmosfera (pela própria superfície, nuvens e elementos que constituem a atmosfera) e, somente, 19 unidades são absorvidas pela atmosfera. Portanto, não é só a energia proveniente diretamente do Sol responsável pelo aquecimento da troposfera. Esta também é aquecida a partir da superfície por 3 processos: condução, convecção e transferência radiativa. $\mathrm{O}$ ar em contato com a superfície aquece por condução e o ar mais acima se aquece por convecção: o ar mais quente próximo à superfície é menos denso e pode flutuar sobre o ar mais frio e denso, com isso, formam-se correntes de convecção em que o ar quente é substituído pelo ar frio (ar frio por ar quente) próximo à superfície (em maiores alturas). Esse processo é similar ao aquecimento d'água 

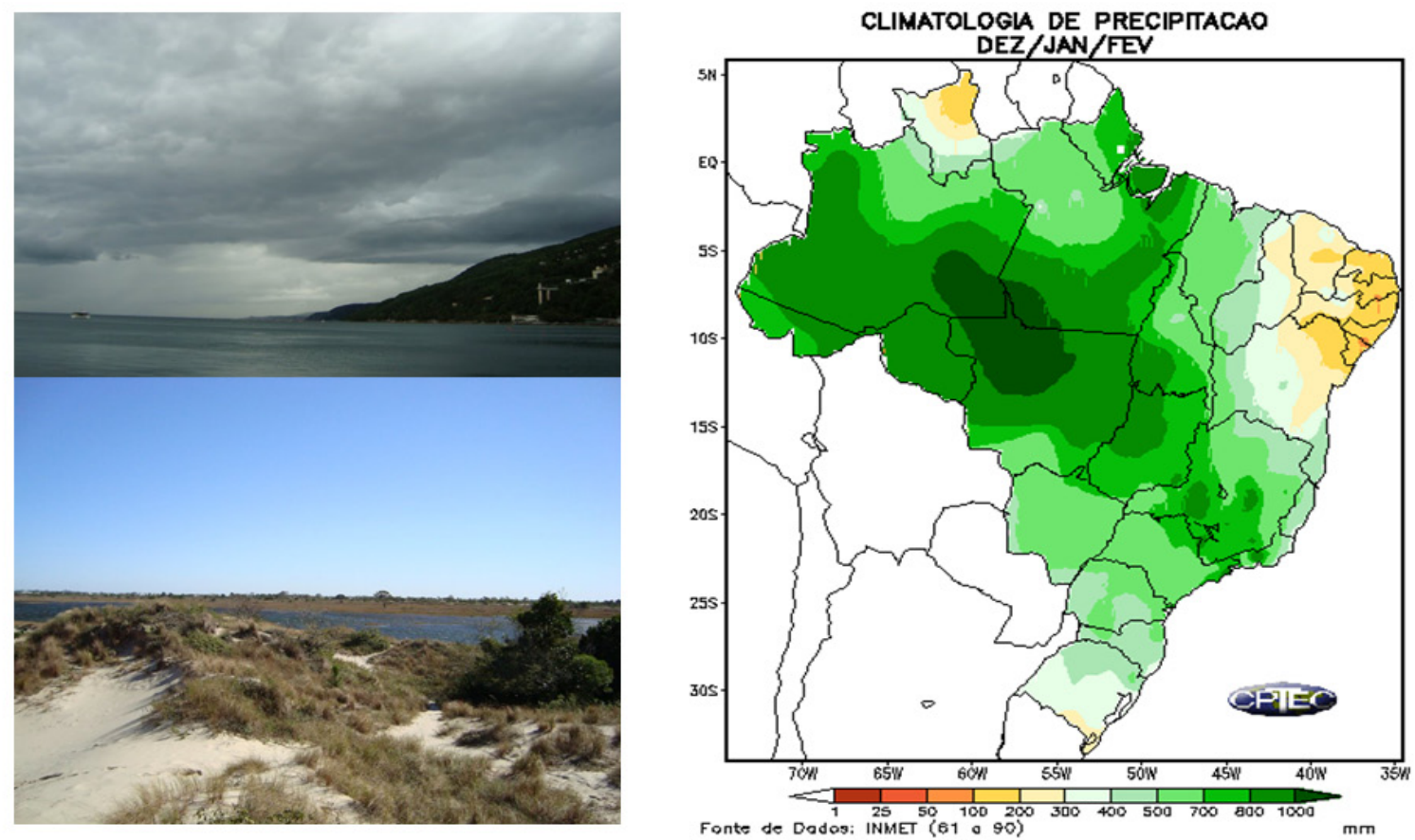

Figura 5. As figuras a esquerda ilustram episódios de tempo, enquanto a da direita, a climatologia de precipitação no Brasil no verão. As fotos são de autoria de Michelle Reboita, enquanto o mapa da climatologia de precipitação foi obtido do Centro de Previsão de Tempo e Estudos Climáticos (CPTEC)

numa chaleira. A convecção não é tão eficiente para aquecer as camadas de ar mais afastadas da superfície terrestre. Essas aquecem pela absorção da radiação que é emitida pela superfície terrestre. Uma vez que a superfície absorve energia solar ela também emite energia, porém com menos intensidade do que a que recebe. A energia emitida pela superfície terrestre é chamada de energia de onda longa e corresponde à radiação com comprimento de onda do infravermelho. Enquanto os gases dióxido de carbono e vapor d'água não são aptos a absorverem a energia proveniente do Sol, eles podem absorver a emitida pela Terra. Portanto, a absorção da radiação terrestre por alguns gases atmosféricos é um fator que promove o aquecimento da troposfera. Devido ao efeito da gravidade, a densidade da atmosfera (número de elementos que constitui a atmosfera por unidade de volume) diminui com a altura. Assim, menos gases são encontrados com o aumento da altura e o aquecimento pelo efeito da radiação vai diminuindo com a altura na troposfera. A transferência radiativa é o principal processo de aquecimento da atmosfera, seguida pela condução e convecção (turbulência).

Toda a explicação precedente foi para justificar a causa das menores temperaturas com o aumento da altura. Entretanto, muitas pessoas se perguntam: como pode ser frio em regiões montanhosas se o topo das montanhas é uma superfície e pode ocorrer os processos de condução, convecção e radiação que aquecem o ar adjacente? Na verdade todos esses processos ocorrem mas devido ao menor número de moléculas (à medida que a altura aumenta) o aquecimento é menor.

As regiões montanhosas também causam influência nos ventos na atmosfera, pois, ao encontrar uma barreira topográfica, uma corrente de ar tende a ascender e, nesse processo, pode ocorrer a formação de nuvens e precipitação. Normalmente, na presença de topografia elevada, ocorre chuva a barlavento (lado em que o ar ascende) e condições secas a sotavento (lado em que o ar desce), pois o ar descendo após cruzar a topografia se aquece e seca o que não favorece a formação de nuvens (Figura 6).

Distância dos oceanos: a capacidade térmica da água é bem maior do que a capacidade térmica da superfície continental: enquanto a água necessita de cerca de quatro unidades de energia para aquecer-se, a terra só necessita de uma unidade de energia. Portanto, o tempo necessário para aquecer e resfriar a água é maior do que para a terra. Assim, a grande capacidade térmica dos corpos d'água reduz as variações de temperatura ao longo do dia nas áreas continentais vizinhas, tanto pela proximidade quanto pela grande quantidade de vapor d'água que é proveniente do oceano e se distribui pelas regiões 


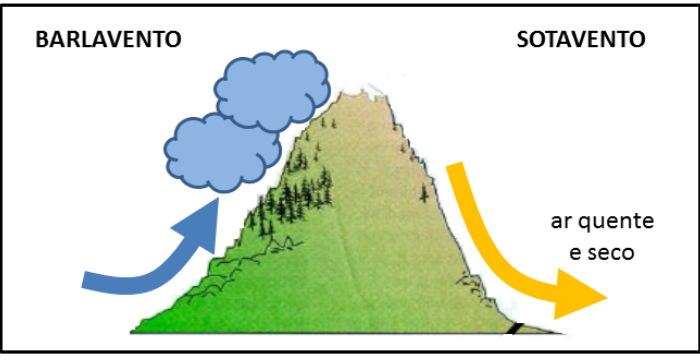

Figura 6. Efeito combinado da topografia e do escoamento atmosférico. $\mathrm{O}$ lado em que o escoamento sobe a montanha é chamado de barlavento e o que desce de sotavento

próximas (Silva Dias e da Silva, 2009). Maior quantidade de vapor d'água significa maior absorção de radiação infravermelha e as temperaturas do ar não baixam muito. Também é válido mencionar o efeito das correntes oceânicas. Uma corrente quente pode ter um efeito moderador sobre um clima frio, como é o caso da corrente do Atlântico Norte que torna o clima europeu mais agradável (menos frio).

Tipo de superfície: algumas superfícies refletem
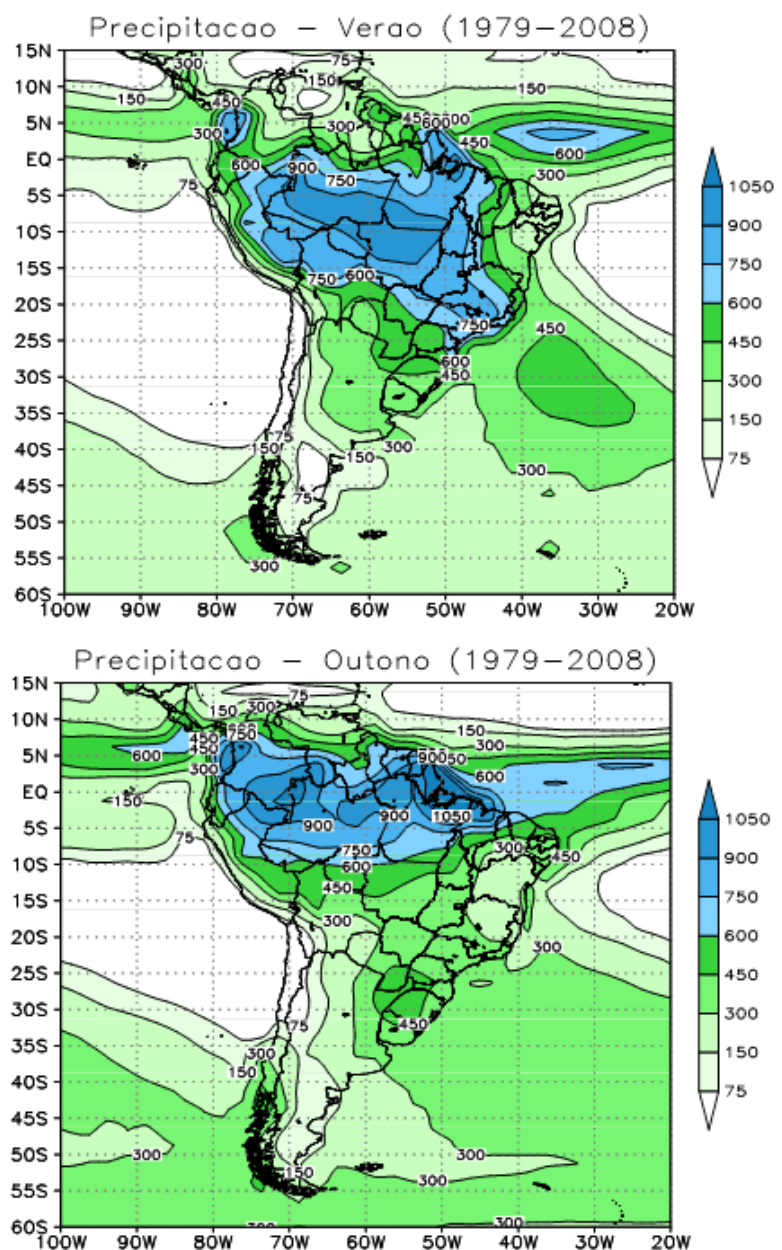

mais energia solar do que outras, portanto, as que mais refletem se aquecerão menos. Um exemplo é o caso da neve e do gelo que refletem aproximadamente $85 \%$ da radiação solar incidente. Já superfícies florestadas refletem cerca de 5 a $20 \%$ da energia solar incidente. É interessante ressaltar que a relação entre a quantidade de radiação solar refletida pela superfície de um objeto e o total de radiação incidente sobre o mesmo recebe o nome de albedo.

Sistemas predominantes de vento e pressão: a seção 3 apresentou o modelo conceitual de circulação geral da atmosfera. Neste modelo, nas regiões entre $20^{\circ}-30^{\circ}$ de latitude, em ambos os hemisférios, ocorrem movimentos nos quais o ar desce da alta para a baixa troposfera, portanto, nestas latitudes predomina um clima seco. Já nas latitudes médias $\left(45^{\circ}\right.$ de latitude, aproximadamente), onde em superfície ocorre a convergência dos ventos provenientes dos polos com os dos subtrópicos, o clima é em geral mais chuvoso, tendo-se em vista que é uma região

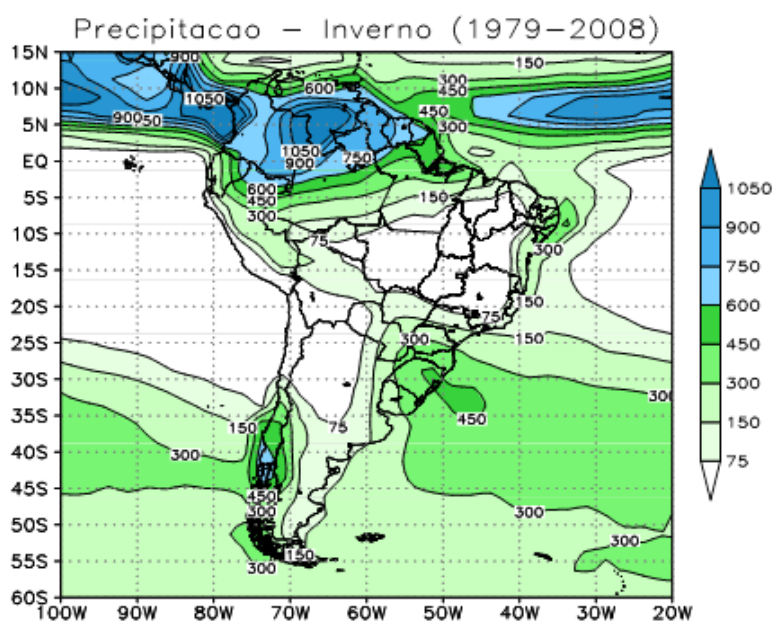

Precipitacao - Primavera (1979-2008)

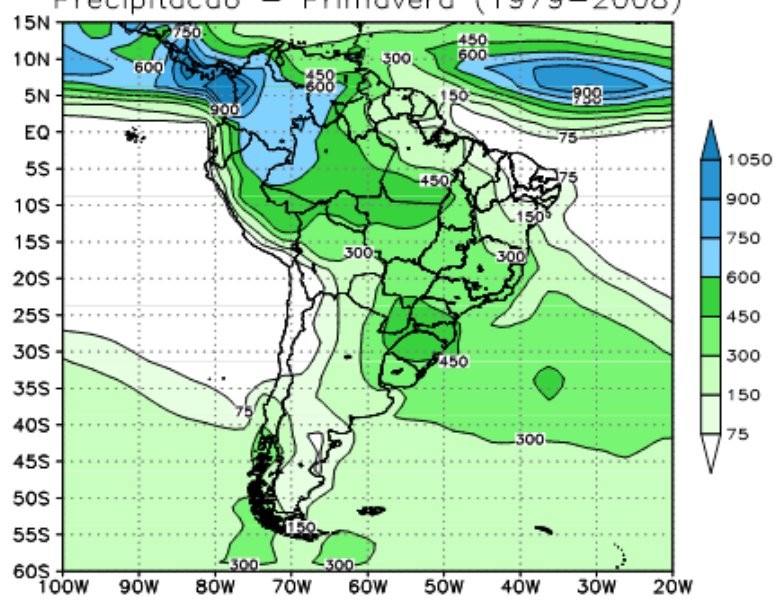

Figura 7. Média sazonal da precipitação $(\mathrm{mm})$ na América do Sul entre 1979 e 2008 com base nos dados do Global Precipitation Climatology Project (GPCP; Adler et al. 2003) 
de formação de frentes e ciclones. Outra região chuvosa é a da convergência dos ventos alísios de sudeste com os de nordeste (ZCIT), que ocorre próxima ao equador. A influência da circulação geral da atmosfera nas diferentes regiões do globo não é tão simples, pois há interação com outros fatores, como por exemplo, com as características geográficas peculiares de cada região.

\section{Climatologia da Precipitação da América do Sul}

A AS estende-se desde $12^{\circ} \mathrm{N}$ de latitude até $55^{\circ} \mathrm{S}$ e possui formas de relevo variadas, como a Cordilheira dos Andes, diversos planaltos e planícies, além de possuir cobertura vegetal não homogênea.
Outro fator importante é que a AS é circundada a oeste pelo oceano Pacífico e a leste pelo oceano Atlântico. Estes fatores combinados proporcionam a atuação e o desenvolvimento de diferentes sistemas atmosféricos que contribuem para a não homogeneidade climática da região.

A precipitação média sazonal na AS no período de 1979 a 2008 é apresentada na Figura 7. A primeira informação importante desta figura é que a precipitação não é distribuída regularmente no tempo e no espaço. Nota-se que o máximo de precipitação migra da região centro-oeste do Brasil durante o verão para o norte do equador durante o inverno. Além disso, observa-se que o norte da AS é uma
Figura 8. Regionalização dos diferentes ciclos anuais de precipitação na América do Sul. R1 corresponde ao sudoeste da AS; R2 ao norte do Chile, noroeste e centrosul da Argentina; R3 ao oeste do Peru, oeste e sul da Bolívia, norte e centro-leste da Argentina e centro-norte do Paraguai; R4 ao sul do Brasil, sul do Paraguai e Uruguai; R5 ao noroeste a sudeste do Brasil; R6 ao norte da região norte do Brasil e litoral do nordeste; R7 ao sertão nordestino do Brasil e R8 ao norte da AS incluindo o estado de Roraima. Fonte: Reboita et al. (2010a)

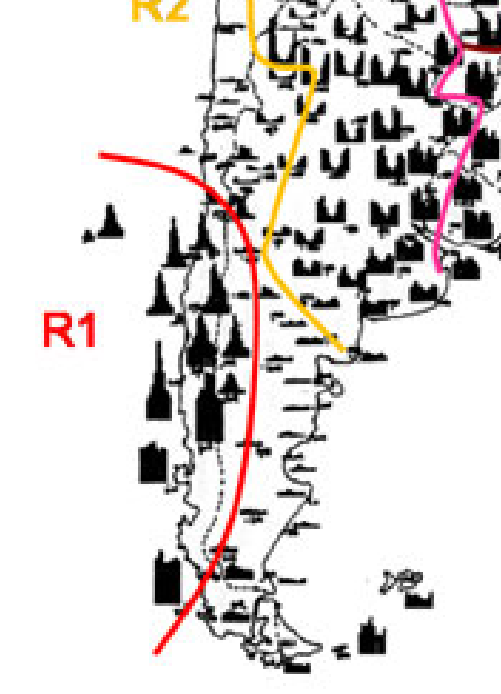

MARCHA ANUAL DAS PRECIPITAÇOESSNA AMÉRICA DO SUL

Periodos predominantes: 1931-60 e 1951-60

Dados cedidos pelo Grupo de Trabalho ATLAS CLIMATICO DE SUDANERICA, para o seminário "EL CUMA DE SUDAMERICA, SEGUN LOS NUEVOS MAPAS CLMMATICOS".

Faculdade de Filosofia e Letras U.6.A. 
região de precipitação abundante durante todo o ano, enquanto o sul da AS é bem seco. É interessante ressaltar que a região centro-oeste do Brasil também é seca durante o inverno.

Próximo à zona equatorial, a Figura 7 também evidencia uma faixa de intensa precipitação no oceano Atlântico que indica a atuação da ZCIT (ver seção 3). Sobre o continente, não é possível identificar claramente a ZCIT, pois a atividade convectiva (devido ao intenso aquecimento radiativo da superfície) interage com a nebulosidade da ZCIT dificultando sua identificação (Taljaard, 1972; Varejão-Silva, 2006). Além disso, as diferentes características de superfície do continente quando comparado com o oceano também dificultam uma formação bem definida da ZCIT . Ao longo do ano,a ZCIT possui uma migração latitudinal alcançando a posição mais austral entre dezembro e maio. Já durante o outono austral, ela contribui para a ocorrência da estação chuvosa no litoral do nordeste do Brasil.

Quando dados de estações meteorológicas são usados para determinar a climatologia anual da precipitação, torna-se evidente a presença de oito regimes de precipitação na AS (Fig. 8). É importante mencionar que a Figura 8 foi extraída do Atlas Climático de Sudamerica (elaborado na Universidade de Buenos Aires), enquanto a divisão dos regimes de precipitação foi elaborada por Reboita et al. (2010a) com base numa análise visual da similaridade (da forma) do ciclo anual da precipitação das

a)

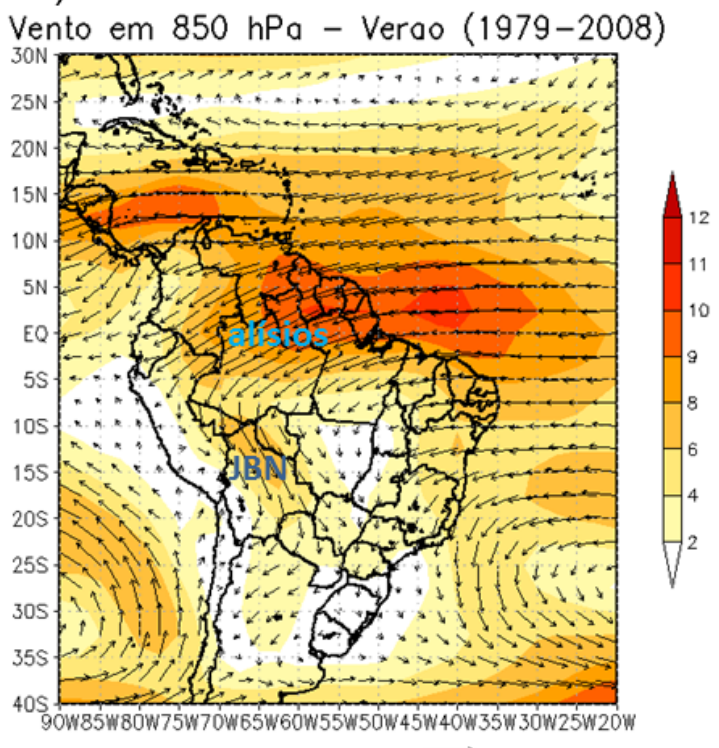

diferentes áreas da AS. Dessa forma, o próximo item apresenta os principais fatores que contribuem para os diferentes regimes de precipitação na AS baseado no estudo de Reboita et al. (2010a).

\section{Regimes de precipitação na AS}

\section{Sudoeste da América do Sul (R1)}

O sudoeste da AS, composto pelo centro-sul do Chile e extremo oeste do centro-sul da Argentina, será denominado de região R1. Nesta região, o ciclo anual de precipitação apresenta máximo no inverno e mínimo no verão, exceto na parte mais sul onde a precipitação é praticamente homogênea ao longo do ano (Fig. 8). O principal sistema atmosférico que influencia a precipitação na R1 é o anticiclone subtropical do Pacífico Sul (ASPS; Aceituno 1980), que é um sistema de alta pressão formado devido a movimentos subsidentes em latitudes subtropicais (ver seção 3).

No inverno, o ASPS atinge sua posição mais norte, influenciando pouco a R1, então, os ventos de oeste que alcançam os Andes, ao cruzá-lo, acabam produzindo precipitação no lado oeste das montanhas (similar ao esquema da Fig. 6). No verão, o ASPS desloca-se para sul e o predomínio de movimento descendente neste sistema inibe a formação de nuvens e, consequentemente, a precipitação. O ASPS também dificulta a passagem

b)

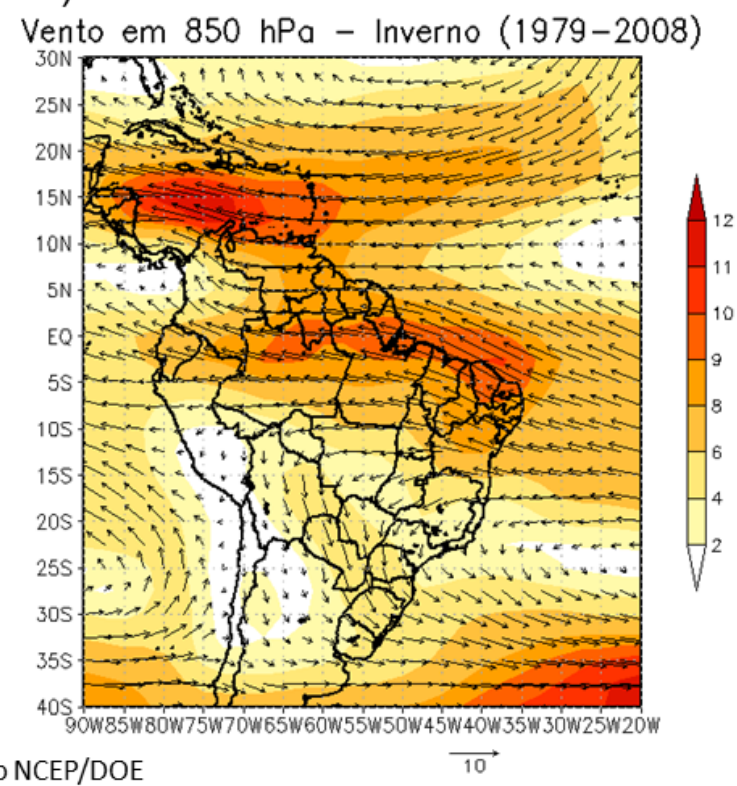

Figura 9. Direção (setas) e magnitude (colorido) do vento em 850 hPa no (a) verão e (b) inverno. Médias calculadas a partir da reanálise do NCEP/DOE (Kanamitsu et al. 2002) no período de 1979 a 2008 
de sistemas atmosféricos como frentes e ciclones. Aqui é válido lembrar que frentes são zonas de contato entre duas massas de ar com características

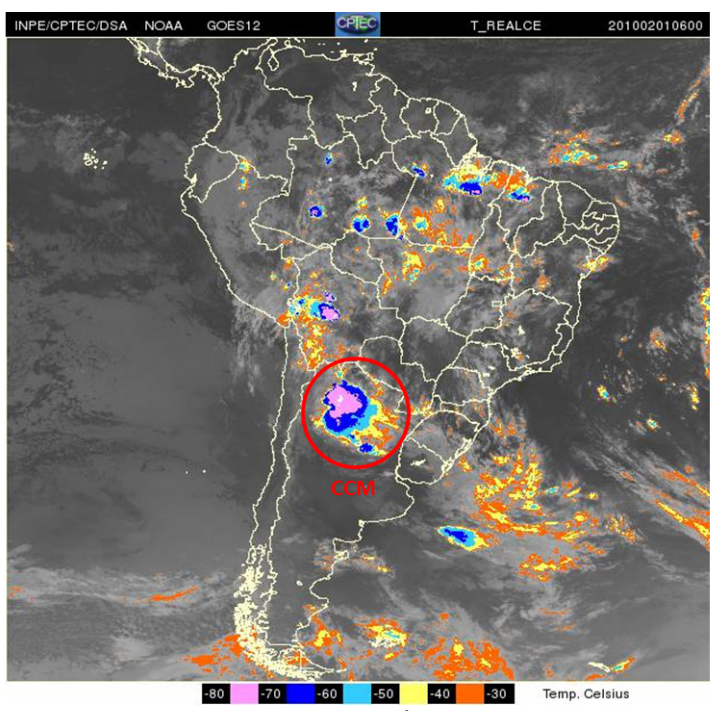

Figura 10. Exemplo da ocorrência de um complexo convectivo de mesoescala (CCM) no dia $1^{\circ}$ de fevereiro de 2010 às 06:00 UTC (03:00 HL) na região R3. Imagem obtida com o satélite GOES12. Fonte: Divisão de Satélites e Sistemas Ambientais (DAS/INPE)

\section{a) Ciclone}

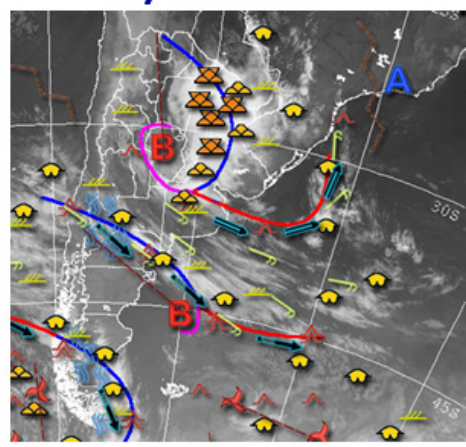

b) VCAN

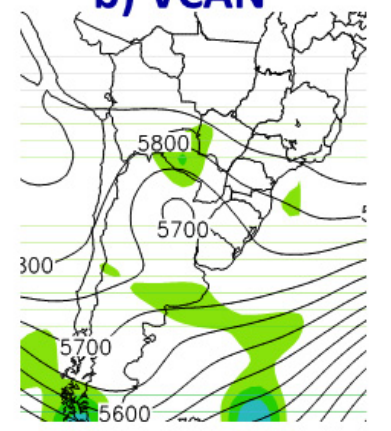

térmicas distintas e que ciclones são regiões de baixa pressão com circulação horária no Hemisfério Sul e que também são sistemas transientes, isto é, que nascem, se deslocam de uma região para outra, e então, se dissipam.

\section{Norte do Chile, Noroeste e Centro-Sul da Argentina (R2)}

A região R2 é formada pelo norte do Chile, noroeste e centro-sul da Argentina e, embora se estenda por um vasto intervalo de latitudes (de $20^{\circ} \mathrm{S}$ a $55^{\circ} \mathrm{S}$ ), o ciclo anual de precipitação é similar. Isto é, a chuva é pouca e praticamente constante ao longo do ano (Fig. 8). No setor norte da R2, o ASPS com seus movimentos descendentes inibe a formação de chuva, sendo o responsável pelos baixos totais pluviométricos nesta área (Aceituno 1980). Já a pouca precipitação no setor sul da R2 é devido aos ventos de oeste que transpõem os Andes, pois, em geral, ocorre precipitação a barlavento da topografia, o que faz com que o ar chegue seco a sotavento. A precipitação que é registrada no sul da R2 deve-se à influência dos sistemas frontais e ciclônicos que cruzam a região ou que se formam na mesma. 
a) Frente Fria

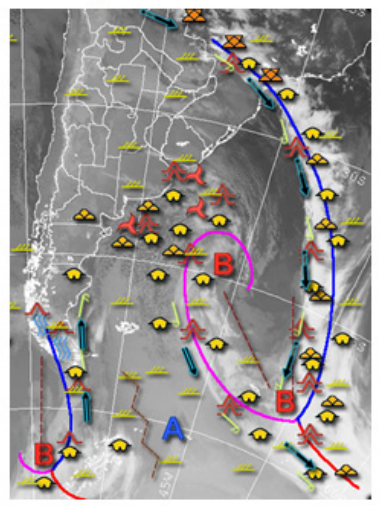

c) Linha de Instabilidade

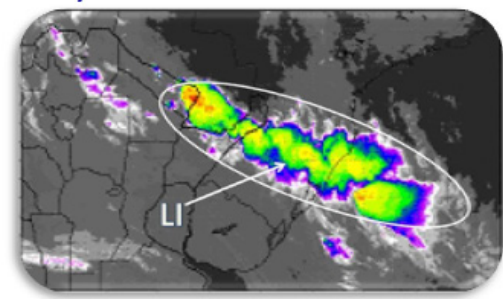

b) Ciclone: 09/03/10

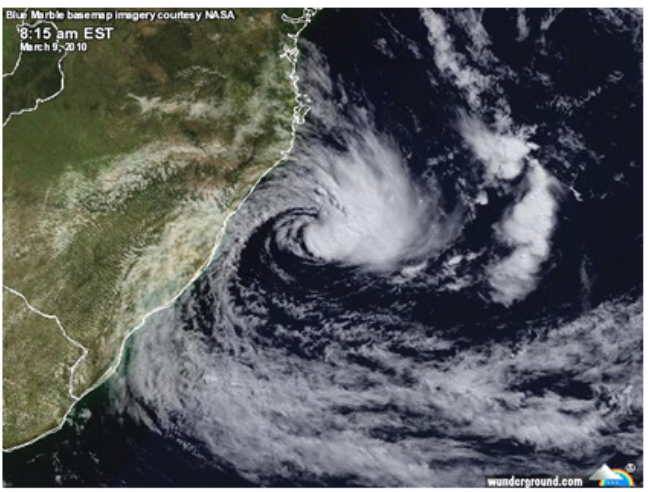

d) Complexo Convectivo de Mesoescala

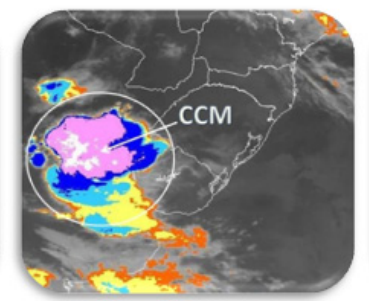

e) Sistema Convectivo Alongado

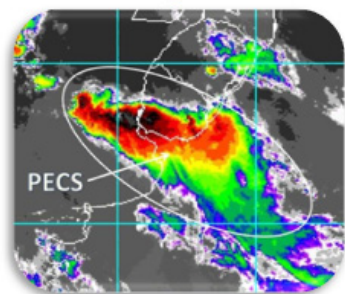

Figura 12. Exemplos de frente fria (a), ciclone (b) e sistemas convectivos de mesoescala (c-e) atuando na R4. A imagem a) foi obtida das nefoanálises do Serviço Meteorológico Nacional da Argentina e b) do National Aeronautics and Space Administration (NASA). Já as imagens c, d e e foram selecionadas no banco de dados da DAS/INPE por Fernandes (2010)

No norte da R2 é onde se encontra o deserto mais árido do mundo, o Atacama, região com precipitação inferior a $100 \mathrm{~mm} / \mathrm{ano}$ (Betancourt et al., 2000).

\section{Oeste do Peru ao Leste da Argentina (R3)}

O oeste do Peru, oeste e sul da Bolívia, norte e centro-leste da Argentina e centro-norte do Paraguai compõem a região R3 onde os maiores totais pluviométricos ocorrem nos meses de verão e os menores nos de inverno (Fig. 8). No verão, o intenso aquecimento da superfície terrestre, em função da grande disponibilidade de energia solar, favorece o desenvolvimento de nuvens convectivas em toda a R3 e este processo contribui para os máximos pluviométricos. Porém, existem outros fatores que influenciam a sazonalidade da precipitação. No verão, os ventos alísios de nordeste estão mais intensos (Drumond et al., 2008; Durán-Quesada et al., 2009; Fig. 9), assim adentram o continente transportando umidade. Esses ventos cruzam a bacia Amazônica e ao encontrarem os Andes no setor norte da R3 sofrem levantamento orográfico e contribuem para a precipitação (Garreaud e Wallace, 1997). Porém, uma parte desses ventos desloca-se em direção aos subtrópicos transportando umidade e, em geral, apresentam um máximo de velocidade em, aproximadamente, $1500 \mathrm{~m}$ acima do nível do mar. Devido a essa última característica, eles recebem o nome de Jato de Baixos Níveis (JBN; Marengo et al., 2004) (Fig. 9a). O JBN a leste dos Andes é importante para a precipitação no centro-sul da R3 porque a umidade transportada contribui para a formação de sistemas convectivos, especialmente os Complexos Convectivos de

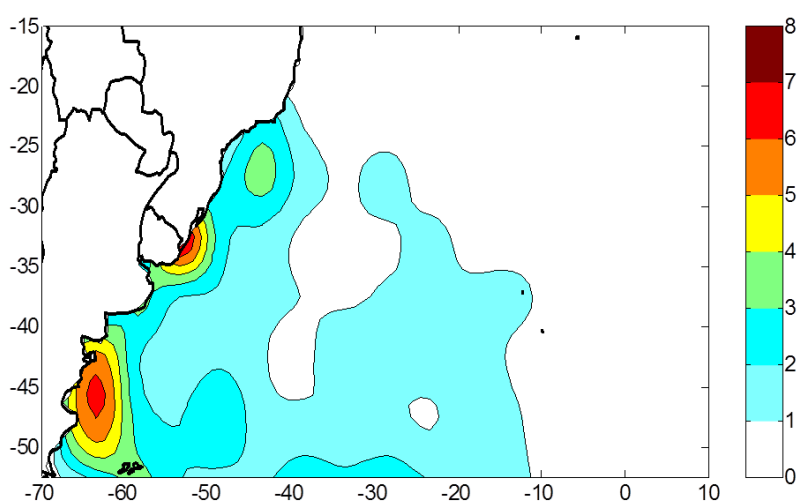

Figura 13. Regiões favoráveis à formação de ciclones na costa leste da América do Sul. A escala de cores se refere à densidade ciclogenética anual $\left(10^{-4} \mathrm{~km}^{-2}\right)$. Adaptado de Reboita (2008) 


\section{Ciclone em 06/05/2008}

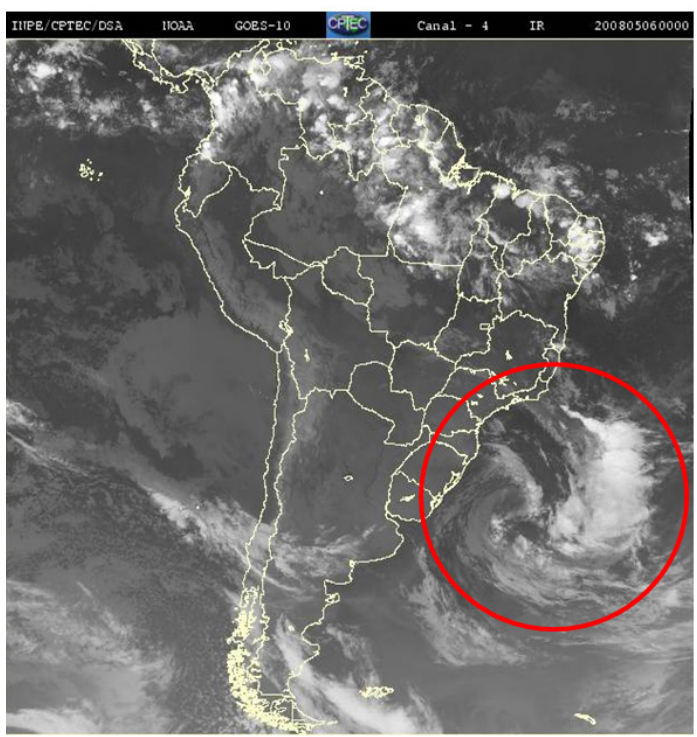

Figura 14. Ciclone ocorrido no dia 06 de maio de 2008. Imagem obtida do DAS/INPE

Mesoescala (CCM). Os CCM são aglomerados de nuvens com forma circular (Fig. 10), que possuem curto tempo de vida (em média 12 horas) e causam precipitação intensa (Silva Dias, 1987; Salio et al., 2007; Saulo et al., 2007).

A precipitação no centro-sul da R3 também pode ser ocasionada, em qualquer época do ano, por frentes frias (Satyamurty e Mattos 1989; Reboita et al. 2009a), ciclones extratropicais/subtropicais (Reboita e Ambrizzi 2006) e vórtices ciclônicos em altos níveis (VCANs; Fuenzalida et al. 2005; Campetella e Possia 2006; Reboita et al. 2010b). Os VCANs são sistemas de baixa pressão com núcleo frio formados em altos níveis da atmosfera (entre 5000 e $11000 \mathrm{~m}$ de altura acima da superfície), mas que em algum estágio do seu ciclo de vida podem se estender até a superfície e influenciar a formação de ciclones também em superfície. Exemplos destes sistemas causadores de precipitação na R3 são apresentados na Figura 11.

\section{Sul do Brasil, Sul do Paraguai e Uruguai (R4)}

A região R4, formada pelo sul do Brasil, sul do Paraguai e Uruguai, tem precipitação bem distribuída ao longo do ano e com totais pluviométricos elevados (Fig. 8). Os totais ainda são maiores no oeste do sul do Brasil na fronteira com o Paraguai. Diferentes sistemas atmosféricos influenciam a precipitação na R4 ao longo do ano, ou seja, os sistemas frontais (Fig. 12a), os ciclones (Fig. 12b), os CCM (Fig. 12c), as linhas de instabilidade (Fig. 12d), os sistemas convectivos alongados persistentes (Fig. 12e), os VCANs (Fig. 11b) e as circulações de brisa.

Como já mencionado, os sistemas frontais correspondem à zona de encontro entre duas massas de ar com propriedades térmicas distintas. Na ocorrência de frentes frias, a massa de ar frio força a massa de ar mais quente a subir, uma vez que esta é menos densa. Isso favorece a formação de nuvens e chuva. Após a passagem de uma frente fria sobre um determinado local, a massa de ar frio, que segue a frente fria, chega até esse e as temperaturas tendem a cair, a precipitação cessa e o tempo, em geral, fica ensolarado. Isto porque a massa de ar frio como é densa e seca desfavorece a formação de nuvens. Nessas situações (com o ar seco e ausência de nuvens), a temperatura durante a noite diminui consideravelmente, pois a superfície terrestre emite praticamente toda radiação infravermelha para o espaço. Quando isso ocorre, o vapor d'água presente no ar próximo da superfície pode condensar formando o orvalho ou até mesmo congelar (situação em que o orvalho é chamado de orvalho congelado). Quando o congelamento ocorre sem haver passagem da água pela fase líquida tem-se as geadas. Esses fenômenos meteorológicos são bastante comuns no sul do Brasil no outono e inverno.

A R4 encontra-se entre duas regiões favoráveis à formação de ciclones: uma na costa sul/sudeste do Brasil e outra entre o Uruguai e o extremo sul do Brasil (Reboita et al. 2009b; Figura 13). Frequentemente, o tempo na R4 é afetado por estes

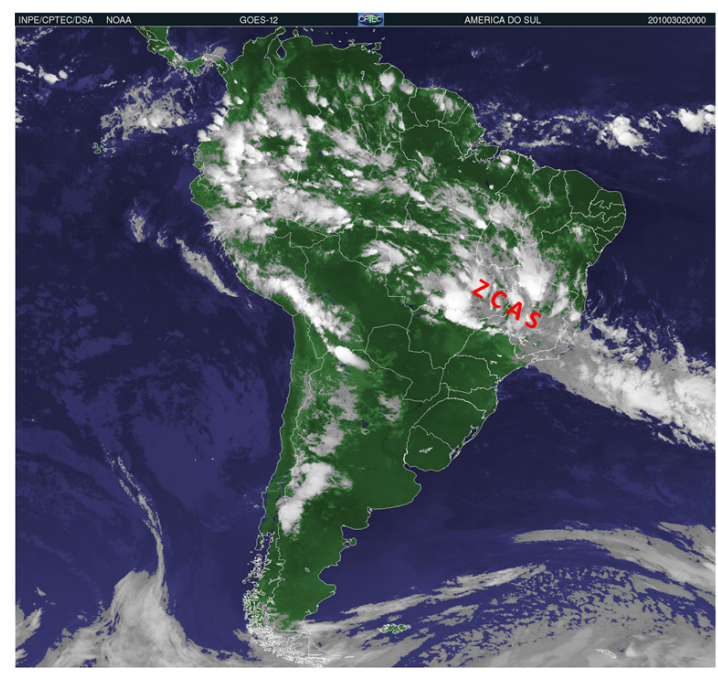

Figura 15. Exemplo de um episódio de Zona de Convergência do Atlântico Sul (ZCAS) no dia 02 de março de 2010. Esta imagem foi selecionada por Ana Carolina Nóbile Tomaziello no banco de dados da DAS/INPE 


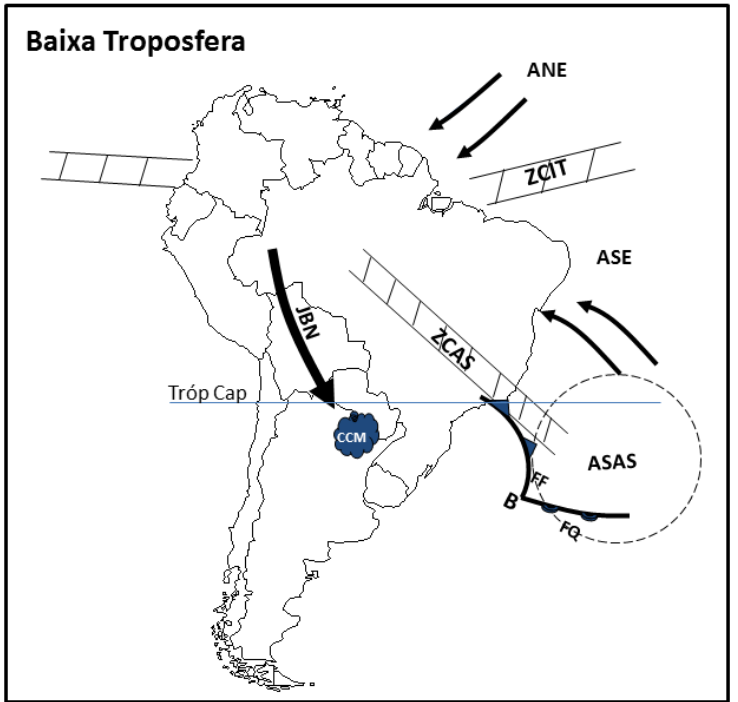

Figura 16. Esquema dos sistemas atmosféricos atuantes na AS no verão (adapt. de Reboita et al. 2010a). A sigla ANE refere-se aos ventos alísios de nordeste, ASE aos ventos alísios de sudeste, ASAS ao anticiclone subtropical do Atlântico Sul, B a uma baixa pressão atmosférica (ciclone), CCM aos complexos convectivos de mesoescala, FF a uma frente fria, FQ a uma frente quente, JBN ao jato de baixos níveis a leste dos Andes, Tróp Cap ao Trópico de Capricórnio, ZCAS à Zona de Convergência do Atlântico Sul e ZCIT à Zona de Convergência Intertropical sistemas que causam ventos fortes, precipitação e redução de temperatura. Um caso que merece ser citado é o do ciclone ocorrido na primeira semana de maio de 2008 (Fig. 14) que num único dia causou chuva acima da média esperada para o mês em Porto Alegre (Reboita et al., 2009c).

Os CCM que atuam na R4 podem se formar sobre esta região ou migrarem da R3 para a R4 (Velasco e Fritsch 1987, Figueiredo e Scolar 1996). As linhas de instabilidade pré-frontais são conjunto de nuvens em forma de linha que se formam na dianteira de um sistema frontal. Já os sistemas convectivos alongados possuem forma diferente dos CCM e das linhas de instabilidade (Fig. 12ce), mas também causam chuvas intensas nas regiões onde ocorrem. Na literatura, é mais comum encontrar trabalhos que documentam a região preferencial de gênese dos sistemas convectivos de mesoescala, que é o nome dado ao conjunto dos sistemas citados (CCMs, LI, sistemas alongados). Por exemplo, Sakamoto (2009) mostra que o norte da Argentina e a região sul do Brasil são as regiões de maior ocorrência desses sistemas.

Um fenômeno que é comum ocorrer em regiões próximas a grandes corpos d'água é a circula-
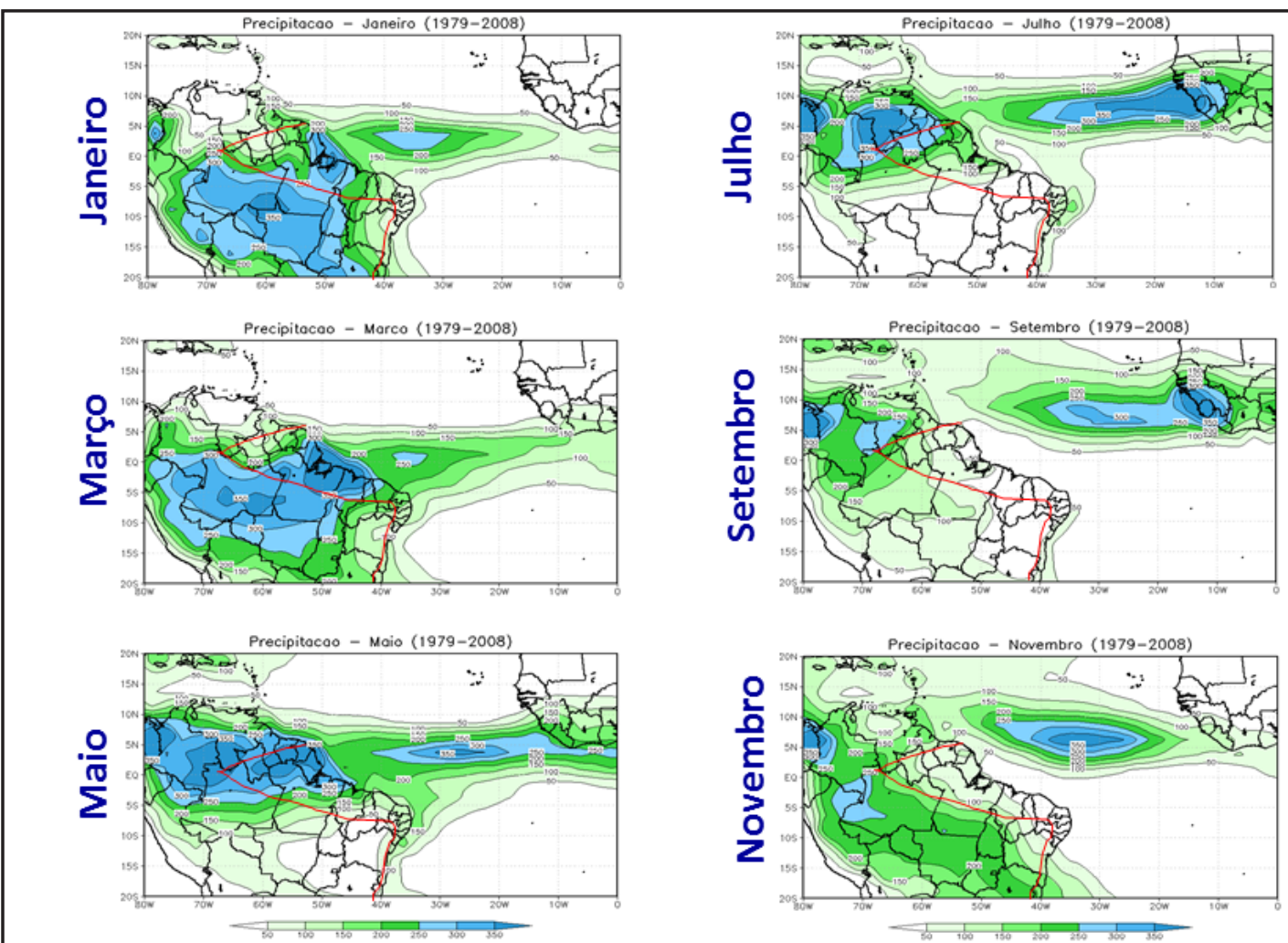

Figura 17. Localização da ZCIT com base em dados médios mensais de precipitação (mm) entre 1979 a 2008 obtidos do GPCP (Adler et al. 2003). A linha vermelha nas figuras delimita a região R6. 


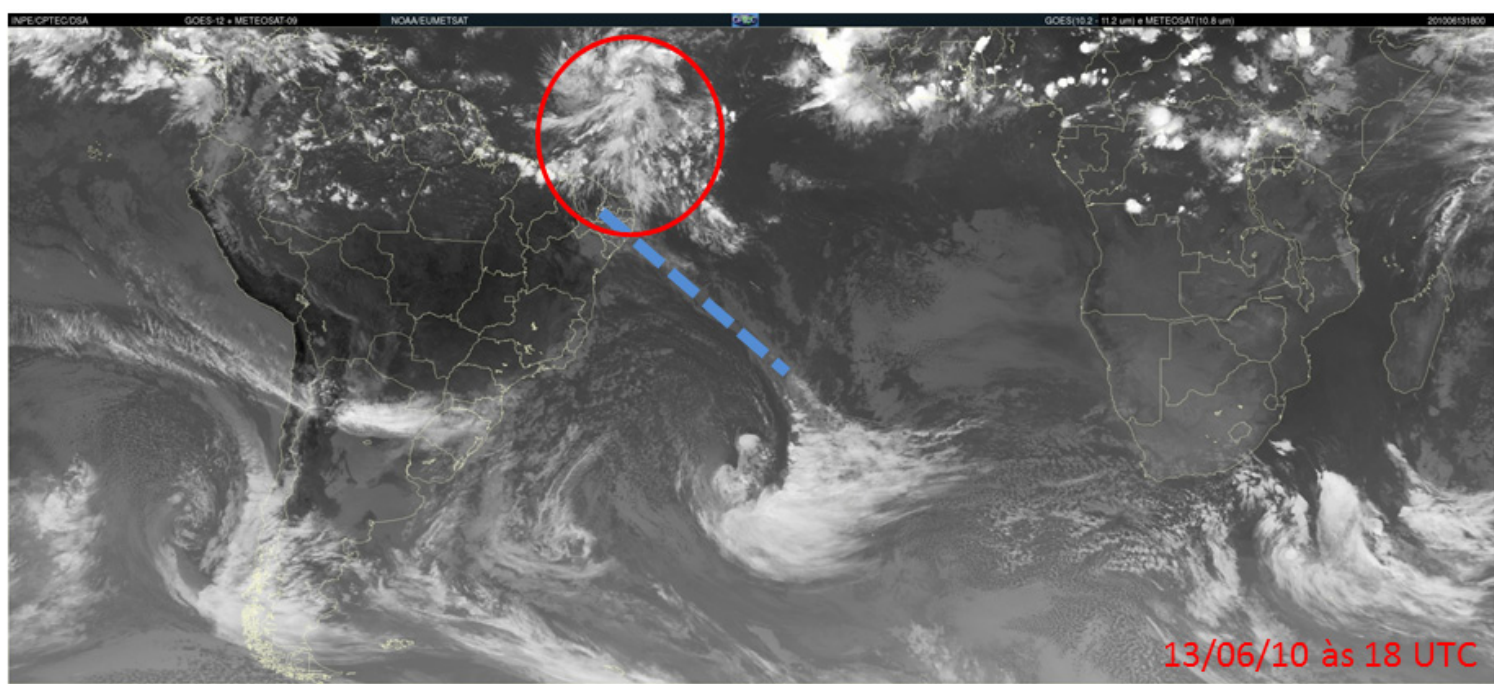

Figura 18. Frente fria (indicada pela linha pontilhada) e onda de leste (indicada pelo círculo) que atuaram na região nordeste do Brasil no dia 13 de junho de 2010. Imagem obtida da DAS/INPE

ção de brisa. $\mathrm{O}$ aquecimento diferenciado entre continente e oceano (ou outro corpo d'água) gera diferenças de temperatura, que formam uma célula de circulação fechada (Atikson, 1981). Durante o dia, como a superfície terrestre se aquece mais rapidamente do que o oceano, a circulação próxima à superfície se dirige do oceano para o continente. Neste caso, tem-se a brisa marítima. Já à noite, o sentido da circulação se inverte, dando origem à brisa terrestre, onde o ar próximo da superfície sopra do continente para o oceano. O transporte de umidade pela brisa marítima para o continente pode fornecer umidade para outros sistemas, por exemplo, para uma frente e causar precipitação.

A R4, além dos sistemas mencionados, sofre a influência indireta da Zona de Convergência do Atlântico Sul (ZCAS) (Kousky, 1988, Kodama, 1992, Quadros, 1994, Nogués-Peagle e Mo, 1997; Ferraz, 2004; Carvalho et al., 2004). Apesar deste sistema atuar climatologicamente sobre o sudeste do Brasil, pode induzir movimentos descendentes intensos no sul do Brasil (Casarin e Kousky, 1986), inibindo a formação de nuvens e precipitação. A ZCAS será definida na R5.

\section{Noroeste a Sudeste do Brasil incluindo ainda o Equador e norte do Peru (R5)}

A R5 abrange uma grande parte da AS, pois se estende desde o Equador e norte do Peru até o sudeste do Brasil (Fig. 8). Nesta área, os totais pluviométricos são máximos no verão e mínimos no inverno.

No verão, os raios solares incidem perpen- diculares no Trópico de Capricórnio, o que gera um maior aquecimento da superfície do que no inverno. Esse aquecimento favorece o levantamento do ar, que é responsável por forte atividade convectiva, ou seja, o ar quente sobe e condensa formando nuvens. Como é verão no Hemisfério Sul, os sistemas atmosféricos estão deslocados para sul, assim, a ZCIT favorece a ocorrência de chuva no norte e nordeste do Brasil. Além disso, nesta época os alísios de nordeste estão mais intensos

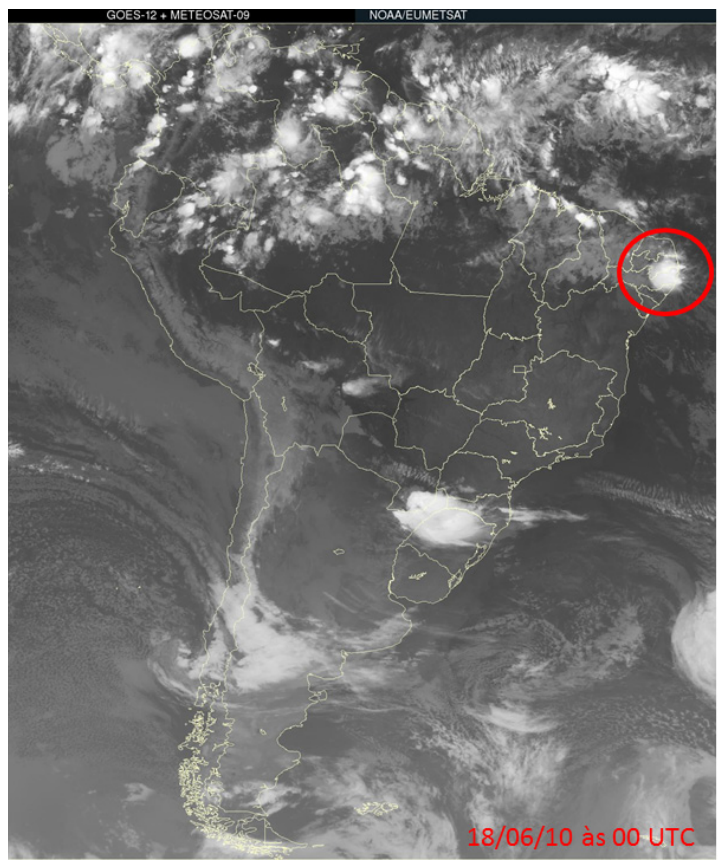

Figura 19. Complexo convectivo de mesoescala (indicado com o círculo vermelho) no dia 18 de junho de 2010 sobre o nordeste do Brasil. Imagem obtida do DAS/INPE 
(Drumond et al., 2008; Durán-Quesada et al., 2009). Estes ventos transportam umidade para o interior do continente e favorecem a formação do Jato de Baixos Níveis (JBN) a leste dos Andes, que por sua vez, transporta umidade para os subtrópicos (Marengo et al., 2004; Vera et al., 2006), contribuindo para a formação de CCM. Ainda no verão, forma-se uma Zona de Convergência de Umidade (ZCOU) sobre o continente, que ocorre devido à interação de vários sistemas (JBN, frentes, ventos do anticiclone subtropical do Atlântico Sul, por exemplo). A ZCOU se estende no sentido noroeste-sudeste desde a Amazônia até o sudeste do Brasil e oceano Atlântico Sul (Grupo de Previsão de Tempo do Instituto Nacional de Pesquisas Espaciais - GPT/INPE). Quando a ZCOU atua durante três dias ou mais passa a ser denominada de Zona de Convergência do Atlântico Sul (ZCAS). Tanto a ZCOU quanto a ZCAS são facilmente identificadas em imagens de satélite (Fig. 15) como uma banda de nebulosidade desde a Amazônia até o oceano Atlântico Sul (Kousky 1988). É importante destacar que esses sistemas causam elevados totais de precipitação sobre a região em que estão atuando. Um exemplo que pode ser mencionado foi o da ZCAS ocorrida no dia 14 de janeiro de 2011 (GPT/INPE) que propiciou a ocorrência de quase $100 \mathrm{~mm}$ de chuva em menos de 24 horas no munícipio de São Paulo, como registrou a estação meteorológica do Instituto de Astronomia, Geofísica e Ciências Atmosféricas (IAG) localizada no Parque da Água Funda. A Figura 16, adaptada de Reboita et al. (2010a), mostra esquematicamente os sistemas atmosféricos sobre a AS no verão e que contribuem para a precipitação na R5. À medida que o inverno se aproxima, os sistemas atmosféricos que tinham se desenvolvido na $\mathrm{R} 5$ no verão enfraquecem e a chuva atinge o mínimo anual.

Alguns sistemas atmosféricos contribuem para a precipitação ao longo de todo o ano no sul da R5, como a passagem de frentes frias, ciclones costeiros, linhas de instabilidade tropicais e pré-frontais e a circulação de brisa. Deve-se destacar que quando uma frente fria alcança a região norte do Brasil o fenômeno é chamado de friagem (Molion, 1987; Seluchi 2009).

\section{Norte da região Norte do Brasil e litoral do Nordeste do Brasil (R6)}

O norte da região norte e o litoral do nordeste do Brasil constituem a região R6 que tem máximos pluviométricos no primeiro semestre do ano (Fig. 8). O sistema atmosférico mais importante para a chuva na R6 é a ZCIT. No verão e outono, este sistema atmosférico atinge sua posição mais sul, contribuindo para o estabelecimento da estação chuvosa na região. Já nas demais estações do ano, a ZCIT migra para norte (Fig. 17) e seu ramo descendente austral atinge a R6 inibindo a precipitação. Independente da época do ano, a chuva durante o dia na R6 pode ser influenciada pela brisa marítima, enquanto à noite pela convergência (encontro) entre a brisa terrestre com os ventos alísios de sudeste (Kousky, 1980). Neste processo, linhas de instabilidade (conjunto de nuvens alinhadas) podem se formar e adentrar o continente. Na R6, ao longo do ano, há um intenso aquecimento radiativo da superfície e isso favorece a convecção, e, consequentemente, a formação de CCM tropicais, que são sistemas que causam chuvas intensas. O leste da R6 também pode ser influenciado pela passagem de sistemas frontais (Kousky, 1979), VCANs (Kousky e Gan, 1981; Gan e Kousky, 1986) e ondas no escoamento de leste (Yamazaki e Rao, 1977; Chou, 1990; Espinoza, 1996). Em junho de 2010, o litoral norte e nordeste da região nordeste do Brasil (principalmente os estados de Alagoas e Pernambuco) sofreu com as altas taxas de precipitação. Entre os dias 13 e 15 de junho de 2010, tal região esteve sob a atuação simultânea de uma frente fria e de uma onda de leste (ondulação nos ventos de leste) que causaram chuvas (Fig. 18). Já no dia 18 de junho formou-se um CCM (Fig. 19) que propiciou mais chuva sobre o estado de Pernambuco. Como na região, provavelmente, já havia excesso de umidade, com o solo encharcado, devido às chuvas causadas pela passagem da frente e da onda de leste, a chuva propiciada pelo CCM levou a ocorrência de inundações que deixaram mais de 60 mil desabrigados conforme relato da imprensa (por exemplo, Jornal Bom Dia Brasil - 21/06/2010).

\section{Sertão Brasileiro (R7)}

A região R7 representa o sertão do nordeste do Brasil, região onde os totais pluviométricos são baixos, mas com um ciclo anual mostrando máximos de precipitação no verão/outono e mínimos no inverno (Fig. 8). No verão e outono, como a ZCIT está localizada no Hemisfério Sul, favorece a precipitação na região, já no inverno a precipitação é inibida pelos movimentos descendentes deste sistema, que agora se localiza no Hemisfério Norte (Fig. 
17) e também pelos movimentos descendentes da atividade convectiva que ocorre no oeste-noroeste da Amazônia. Outros sistemas como, por exemplo, frentes frias e VCANs quando chegam até o sertão nordestino também podem causar chuva.

É interessante ressaltar que os ventos alísios de leste provenientes do oceano e carregados de umidade são importantes para a precipitação na R6, mas não na R7. Uma explicação estaria associada com o relevo da região: o planalto da Borborema é uma barreira topográfica para o escoamento atmosférico. Assim, sugere-se que os ventos de leste, ao encontrarem a barreira topográfica, ascendam favorecendo precipitação orográfica no lado leste da montanha e, dessa forma, os ventos de leste chegam secos na R7. Além disso, os ventos de leste transportam ar mais frio do oceano para o sertão do Brasil e é possível que ao penetrarem na R7 sejam aquecidos e a umidade relativa do ar diminua (Reboita et al. 2010a). O fenômeno dificulta a formação de nuvens e, consequentemente, de chuva. Entretanto, acredita-se que a causa dos baixos totais pluviométricos na R7 esteja mais associado com mecanismos dinâmicos de grande escala do que com a topografia regional.

\section{Norte da América do Sul (R8)}

A região R8 abrange o norte da AS onde a precipitação é elevada durante todo o ano, mas ainda apresentando maiores valores no inverno (Fig. 8). Isto ocorre em função da ZCIT estar na sua posição mais norte, ou seja, atuando diretamente na R8. Já no verão, quando a ZCIT desloca-se para sul desfavorece um pouco a precipitação em tal região (Fig. 17). Além da ZCIT, ondas de leste, cavados em altos níveis (Riehl, 1977), convecção local, CCM, circulação de brisa e linhas de instabilidade são sistemas que contribuem para a precipitação na R8.

\section{Conclusões}

Este estudo apresentou uma visão resumida, mas integrada, do entendimento do tempo e clima na AS. Foi mostrado que a precipitação na AS possui uma grande variabilidade espacial e temporal que está associada tanto a fatores ligados à circulação geral da atmosfera (ventos alísios, anticiclones subtropicais), quanto a sistemas meteorológicos de escala espacial mais reduzida (frentes frias, ciclones subtropicais e extratropicais, circulações de brisa, entre outros) que interagem com as características locais do continente (topografia, proximidade com o oceano, etc.). Este trabalho pode servir como um guia inicial para os que têm interesse em entender a climatologia da AS e servir de material complementar para aqueles que já estão familiarizados com o assunto.

\section{Referências}

Aceituno P. 1980. Relation entre la posicion del anticiclon subtropical y la precipitación en Chile. Relatório do Projeto $n^{\circ}$ E.551.791 do Departamento de Geofísica da Universidade do Chile. 14 p.

Adler R.F., Huffman G.J., Chang A., Ferraro A., Xie P.P., Janowiak J., Rudolf B., Schneider U., Curtis S., Bolvin D., Gruber A., Susskind J., Arkin P., Nelkin E. 2003. The version-2 Global Precipitation Climatology Project (GPCP) Monthly Precipitation Analysis (1979-present). J. Hydrometeorology, 4:1147-1167.

Atkinson B.W. 1981. Mesoescale Atmospheric Circulations. London Acad. Press. 495.

Atlas Climático de Sudamerica. Mapa 4. URL: $<$ http://www.master.iag.usp.br/ind. php? inic $=00 \&$ prod $=$ ensino\&pos $=2>$. Acesso: 08.01.2009.

Betancourt J.L., Latorre C., Rech J.A., Quade J., Rylander K.A. 2000. A 22.000-Year Record of Monsoonal Precipitation from Northern Chile's Atacama Desert. Science, 289:1542-1546.

Campetella C., Possia N. 2006. Upper-level cut-off lows in southern South America. Meteorology and Atmospheric Physics, 96 (1-2):181-191.

Carvalho L.M.V, Jones C., Liebmann B. 2004. The South Atlantic convergence zone: Intensity, form, persistence, and relationships with intraseasonal to interannual activity and extreme rainfall. $J$. Climate, 17:88-108.

Casarin D.P., Kousky V.E. 1986. Anomalias de precipitação no sul do Brasil e variações na circulação atmosférica. Revista Brasileira de Meteorologia, 1:83-90.

Chou S.C. 1990. Análise de distúrbios ondulatórios de leste sobre o oceano Atlântico Equatorial Sul. INPE - 5222 - TDL / 437. (Dissert. Mestr.).

Drumond A., Nieto R., Gimeno L., Ambrizzi T. 2008. A Lagrangian identification of major sources of moisture over Central Brazil and La Plata Basin. J. Geophys. Res., 113. D14128, doi:10.1029/2007JD009547.

Durán-Quesada A.M., Reboita M.S., Gimeno L., Nieto R. 2009. The role of the tropics in the global water cycle: Precipitation and moisture transport in Tropical America. In: Esa-Esrin Conference: Earth Observation and Water Cycle Science: "towards a water cycle multi-mission strategy", Frascati, Itália.

Espinoza E.S. 1996. Distúrbios nos Ventos de Leste no Atlântico Tropical. São José dos Campos: Inst. Nac. 
Pesq. Espaciais. 149p.

Fernandes D.S. 2008. Caracterização das Tempestades a partir dos canais Infravermelho e Vapor d'água do Satélite GOES 10 e 12. São Paulo: Inst. Astron., Geof. e C. Atmosf., IAG-USP. 144p.

Ferraz S. E.T. 2004. Variabilidade Intrasazonal da Precipitação sobre o Sudeste Brasileiro. São Paulo: Inst. Astron., Geof. e C. Atmosf., IAG-USP.

Figueiredo J.C., Scolar J. 1996. O Tempo de Vida Médio dos Sistemas Convectivos de Mesoescala na América do Sul. In: Congresso Brasileiro de Meteorologia, 9. Anais ... Campos de Jordão, SP, p. 984-986.

Fuenzalida H., Sánchez R., Garreaud R. Sept. 2005. A climatology of cutoff lows in the Southern Hemisphere.J. Geophys. Res., 110:1-10. D18101 10.1029/2005JD005934.

Gan M.A., Kousky V.E. 1986. Vórtices ciclônicos da alta troposfera no oceano Atlântico Sul. Rev. Bras. Meteorologia, 1:19-28.

Garreaud R.D., Wallace J.M. 1997. The diurnal of convective cloudiness over the Americas. Monthly Weather Review, 125:3157-3171.

Grupo da Previsão de Tempo do Instituto Nacional de Pesquisas Espaciais - GPT/INPE. URL: < http:// www.cptec.inpe.br >. Acesso: 10.04.2011.

Jacobson M. Z. 2005. Fundamentals of Atmospheric Modeling. $2^{\mathrm{a}}$ Ed., Cambridge Univ. Press.

Jetstream - Online School for Weather. URL: < http://www.srh.noaa.gov/jetstream/tropics/tc_ classification.htm >. Acesso: 02.09.2010.

Jornal Bom Dia Brasil. Chuvas no Nordeste deixam mais de 60 mil desalojados. URL: < http://g1.globo. com/bom-dia-brasil/noticia/2010/06/chuvas-no-nordeste-deixam-mais-de-60-mil-desalojados. html>. Acesso: 10.08.2010.

Kalnay E., Kanamitsu M., Kistler R., Collins W., Deaven D., Gandin L., Iredell M., Saha S., White G., Woollen J., Zhu Y., Leetmaa A., Reynolds R., Chelliah M., Ebisuzaki W., Higgins W., Janowiak J., Mo K.C., Ropelewski C, Wang J., Jenne R., Joseph D. 1996. NCEP/NCAR 40-year Reanalysis Project. Bull. Am. Meteorol. Soc., 77:437-471.

Kanamitsu M., Ebisuzaki W., Woollen J., Yang S-K., Hnilo J.J., Fiorino M., Potter G.L. 2002. NCEP-DOE AMIP-II Reanalysis (R-2). Bull. Am. Meteorol. Soc., 83:1631-1643.

Kodama Y.-M. 1992. Large-scale common features of subtropical precipitation zones (the Baiu frontal zone, the SPCZ, and the SACZ), Part I: Characteristics of subtropical frontal zones. J. Meteorological Society of Japan, 70:813-835.

Kousky E.V. 1980. Diurnal rainfall variation in northeast Brazil. Monthly Weather Review, 108:488-498.

Kousky V.E. 1979. Frontal Influences on Northeast Brazil. Monthly Weather Review, 107:1140-1153.

Kousky V.E. 1988. Pentad outgoing longwave radia- tion climatology for the South American sector. Revista Brasileira de Meteorologia, (3):217-231.

Kousky V.E., Gan M.A. 1981. Upper tropospheric cyclonic vortices in the tropical South Atlantic. Tellus, 36(6):538-551.

Marengo J.A., Soares W.R., Saulo C., Nicolini M. 2004. Climatology of the Low-Level Jet East of the Andes as Derived from NCEP-NCAR Reanalyses: Characteristics and Temporal Variability. J. Climate, 17 (12):2261-2280.

Mctaggart-Cowan R., Bosart L., Davis C.A., Atallah E.H., Gyakum J.R. , Emanuel K.A. 2006. Analysis of Hurricane Catarina (2004). Monthly Weather Review, 134:3029-3053.

Molion L.C.B. 1987. Climatologia da Região Amazônica: Mecanismos de Precipitação. Revista Brasileira de Meteorologia, 2:107-117.

Nogués-Peagle J., Mo K.C. 1997. Alternating wet and dry conditions over South America during summer. Monthly Weather Review, 125:279-291.

Quadro M.F.L. 1994. Estudo de Episódios de Zona de Convergência do Atlântico Sul ZCAS sobre a América do Sul. São José dos Campos: INPE.

Reboita M.S. 2008. Ciclones Extratropicais sobre o Atlântico Sul: Simulação Climática e Experimentos de Sensibilidade. São Paulo: Inst. Astron., Geof. e C. Atmosf., IAG-USP. 359p.

Reboita M.S., Ambrizzi T. 2006. Monitoramento dos Ciclones Extratropicais no Hemisfério Sul. In: Congresso Brasileiro de Meteorologia, 14, Anais... Florianópolis, SC, CD-ROM.

Reboita M.S., Ambrizzi T., da Rocha R. P. 2009a. Relationship between the Southern Annular Mode and Southern Hemisphere Atmospheric Systems. Revista Brasileira de Meteorologia, 24 (1):48-55.

Reboita M.S., da Rocha R.P., Ambrizzi T., Sugahara S. 2009b. South Atlantic Ocean Cyclogenesis Climatology Simulated by Regional Climate Model (RegCM3). Climate Dynamics, doi:10.1007/ s00382-009-0668-7.

Reboita M.S., Gan M. A., da Rocha R. P., Ambrizzi T. 2010a. Regimes de Precipitação na América do Sul: Uma Revisão Bibliográfica. Revista Brasileira de Meteorologia, 25(2):185-204.

Reboita M.S., Iwabe C.M.N., da Rocha R.P., Ambrizzi T. 2009c. Análise de um Ciclone Semi-Estacionário na Costa Sul do Brasil Associado a Bloqueio Atmosférico. Revista Brasileira de Meteorologia, 24 (4):407-422.

Reboita M.S., Nieto R.N., Gimeno L., da Rocha R.P., Ambrizzi T., Garreaud R., Krüger L. F. 2010b. Climatological Features of Cutoff Low Systems in the Southern Hemisphere. J. Geophys. Res., 115. D17104, doi:10.1029/2009JD013251.

Riehl H. 1977. Venezuelan rain systems and the general circulation of the Summer tropics II: Relations between low and high latitudes. Monthly Weather 
Review, 105(11):1421-1433.

Sakamoto M. 2009. Sistemas Convectivos de Mesoescala observados na Região Subtropical da América do Sul durante o SALLJEX. São Paulo: Inst. Astron., Geof. e C. Atmosf., IAG-USP. 281 p.

Salio P., Nicolini M., Zipser J. 2007. Mesoscale convective systems over southeastern South American low-level jet. Monthly Weather Review, 135:1290-1309.

Satyamurty P., Mattos L.F. 1989. Climatological lower tropospheric frontogenesis in the midlatitudes due to horizontal deformation and divergence. Monthly Weather Review, 117(6):1355-1364.

Saulo C, Ruiz J., Skabar Y.G. 2007. Synergism between the Low-Level Jet and Organized Convection at Its Exit Region. Monthly Weather Review, 135:1310-1326.

Seluchi M.E. 2009. Geadas e Friagens. In: Cavalcanti I.D.A., Ferreira N. J., da Silva M.G.A.J., Silva Dias M.A.F. (Orgs.). Tempo e Clima no Brasil. São Paulo: Ofic. Textos. p. 149-167.

Silva Dias M.A.F. 1987. Sistemas de Mesoescala e Previsão de Tempo a Curto Prazo. Revista Brasileira de Meteorologia, 2:133-150.

Silva Dias M.A.F., da Silva M.G.A.J. 2009. Para Entender Tempo e Clima. In: Cavalcanti I.D.A., Ferreira N.J., da Silva M.G.A.J., Silva Dias M.A.F. orgs. Tempo e Clima no Brasil. São Paulo: Ofic. Textos. p. 15-21.
Síntese Sinótica Mensal. Cachoeira Paulista. URL: <http://www7.cptec.inpe.br/noticias/faces/noticias. jsp?idConsulta $=\&$ idQuadros $=109>$. Acesso: 02.09.2010.

Taljaard J.J. 1972. Synoptic meteorology of the Southern Hemisphere. In Newton. C.W. ed. Meteorology of the Southern Hemisphere. American Meteorologícal Society, Boston, MA.

Varejão-Silva M.A. 2006. Meteorologia e Climatologia. Brasília: INMET. 463p.

Velasco I., Fritsch J.M. 1987. Mesoescale Convective Complexes in the Américas. J. Geophys. Res., 92:959-9613.

Vera C., Baez J., Douglas M., Emmanuel C. B., Marengo J., Meitin J., Nicolini M., Nogues-Paegle J., Paegle J., Penalba O., Salio P., Saulo C., Silva Dias M. A., Silva Dias P. S., Zipser E. 2006. The South American Low-Level Jet Experiment. Bull. Am. Meteorol. Soc., 87:63-77.

WMO no 100. 1983. Guide to Climatological Practices, 2 ed., Secretariat of the World Meteorological Organization, Geneva.

Yamazaki Y., Rao V.B. 1977. Tropical cloudiness over South Atlantic Ocean. J. Meteor. Soc. Japan, 55 (2):205-207.

NCEP/NCAR 1996. 40-year Reanalysis Project. Bulletin of the American Meteorological Society, 77:437-471. 